\section{A Program Aimed toward Inclusive Excellence for Underrepresented Undergraduate Women in the Sciences}

\author{
Laura A. Katz, ${ }^{\dagger}$ Kathryn M. Aloisio, ${ }^{\ddagger}$ Nicholas J. Horton, $\$$ Minh Ly, ${ }^{\ddagger}$ Sara Pruss," Kate \\ Queeney," Cate Rowen," and Patricia Marten DiBartolo"* \\ tDepartment of Biological Sciences, "Institutional Research, "Department of Geosciences, \\ 'Department of Chemistry, and "Department of Psychology, Smith College, Northampton, \\ MA 01063; \&Department of Mathematics and Statistics, Amherst College, Amherst, MA 01002
}

\begin{abstract}
Created to foster inclusive excellence, Smith College's Achieving Excellence in Mathematics, Engineering, and Science (AEMES) Scholars program provides early faculty-mentored research opportunities and other programming as a way to foster success in academic outcomes for underrepresented women in science. Using academic record data, we compared Scholars' outcomes over time with those of underrepresented students before program launch and to relevant peer comparison groups. Since its launch, AEMES Scholars have achieved significantly higher gateway life sciences course grade point averages (GPAs), rates of persistence in life and natural sciences, and participation in natural sciences advanced research relative to baseline. Gains for Scholars in gateway course GPA eliminated the significant gap that previously existed between science, technology, engineering, and mathematics (STEM)-underrepresented and other students, whereas gains in natural sciences persistence now has Scholars continuing in STEM at significantly higher rates than all other students. Many of the gains for AEMES Scholars were echoed in findings of improved outcomes for our STEM students overall since AEMES' launch. Underrepresented students who were not part of the Scholars program also evidenced increased gateway course GPA over this same period. We discuss potential explanations for these outcomes and ongoing work aimed at achieving further inclusive excellence for women in the sciences.
\end{abstract}

\section{INTRODUCTION}

In 2015, the Association of American Colleges and Universities (AACU) released a report calling for concerted efforts to promote access and diversity in higher education so that future generations of leaders reflect the diversity of our world. This echoes a series of calls for inclusive excellence in science, technology, engineering, and mathematics (STEM) over the past 10 years (Hill et al., 2010; National Academy of Sciences, National Academy of Engineering, and Institute of Medicine, 2011; President's Council of Advisors on Science and Technology [PCAST], 2012; Zorn et al., 2014). Advocates of equity in STEM education cite various reasons to invest in these efforts, ranging from social justice imperatives to economic market competition (Anderson and Kim, 2006; PCAST, 2012; AACU, 2015). Compelling evidence also indicates that a diverse workforce is essential for innovation in STEM, given that efficient discovery and dissemination of knowledge requires a multitude of backgrounds and perspectives (Hong and Page, 2004; Freeman and Huang, 2014, 2015).

Nonetheless, loss of talented students interested in STEM remains a persistent problem. Underrepresented minority (URM) students now report an interest in majoring in a STEM discipline at rates equivalent to their white peers, yet have significantly lower 4- and 5-year STEM degree completion rates (Anderson and Kim, 2006;
Pat Marsteller, Monitoring Editor Submitted January 15, 2016; Revised December 1, 2016; Accepted December 12, 2016

CBE Life Sci Educ March 1, 2017 16:ar11 DOI:10.1187/cbe.16-01-0029

*Address correspondence to: Patricia Marten DiBartolo (pdibarto(asmith.edu).

() 2017 L. A. Katz et al. CBE-Life Sciences Education (@) 2017 The American Society for Cell Biology. This article is distributed by The American Society for Cell Biology under license from the author(s). It is available to the public under an Attribution-Noncommercial-Share Alike 3.0 Unported Creative Commons License (http:// creativecommons.org/licenses/by-nc-sa/3.0). "ASCBß" and "The American Society for Cell Biology $\circledR^{\prime \prime}$ are registered trademarks of The American Society for Cell Biology. 
Higher Education Research Institute [HERI], 2010) and earn undergraduate degrees or work in science and engineering at much lower rates than their representation in the population (National Academy of Sciences, National Academy of Engineering, and Institute of Medicine, 2011; National Science Board [NSB], 2014). Similarly, low-income and first-generation college student status has also been related to lower levels of STEM persistence and/or academic success (cf. Aronson, 2008). Chen and Carroll (2005) found that first-generation college students (i.e., those from families in which neither parent attained any education beyond high school) were less likely to choose a math or science major, and when they did, had lower major GPAs than students whose parents had a bachelor's degree or higher. First-generation students in this study were also more likely to come from a low-income family and belong to an underrepresented minority group (Chen and Carroll, 2005). Another longitudinal study of transcript-based data for a nationally representative sample found that students who majored in STEM but did not complete an undergraduate degree were more likely than completers to be the first in their families to go to college, to come from low-income families, and to work for $15 \mathrm{~h}$ or more a week (Anderson and Kim, 2006).

As Leggon (2010) notes, the intersection and interaction of demographic variables and social identities such as race and family status can complicate the understanding of individuals' academic and career trajectories. Gender is another demographic variable related to STEM success, especially in relation to these other factors, with men continuing to outnumber women in many STEM disciplines from earned bachelor's degrees to earned PhDs, particularly at the upper levels of those professions (Hill et al., 2010; NSB, 2014). Williams et al.'s (2014) interview study of 60 female professors in STEM who were women of color found evidence of significant reported gender as well as racial bias, revealing that their identities created a form of perceived "double jeopardy" related to others' judgments about their belongingness, competence, and success as scientists.

Clearly, extant data indicate the importance of targeting students who come from historically STEM-underrepresented groups related to race, gender, and family status. Reports within the past decade (Anderson and Kim, 2006; Hill et al., 2010; National Academy of Sciences, National Academy of Engineering, and Institute of Medicine, 2011; PCAST, 2012; Zorn et al., 2014) forcefully assert that institutions of higher education have a responsibility to attract and retain students from underrepresented groups in order to broaden participation and increase STEM talent. Yet, Aronson (2008) notes the impact of "funneling inequality" (p. 43) in higher education. This notion acknowledges the difficulties minority, first-generation, and/or low-income students have in gaining access to the same high-quality educational outcomes and experiences enjoyed by their peers from more privileged backgrounds, sometimes even within the same institution. Here, we present an empirical evaluation of Smith College's programmatic efforts to broaden participation for underrepresented women in the sciences at a women's liberal arts college.

In 2006, a Smith delegation attended the meeting "Symposia on Diversity in the Sciences" sponsored by the Howard Hughes Medical Institute (HHMI). Participating institutions were charged with analyzing key academic outcomes for their students of color in STEM (HHMI, 2007). Smith College, one of the largest women's liberal arts colleges in the United States, has a core commitment to educational access in order to fulfill its mission to "educate women of promise for lives of distinction." Despite Smith's strong rate of life sciences baccalaureate degree production (avg. 10.26\% from 2004-2013) relative to national rates for women (6.06\% from 2004-2013; National Science Foundation, 2015), our 2006 analyses produced a disconcerting result: historically underrepresented students, both students of color and first-generation college students, were taking life sciences gateway courses in high numbers but tended to underperform in them (e.g., receive lower course grades).

To foster inclusive excellence, the AEMES programs (Achieving Excellence in Mathematics, Engineering, and Science) were launched in 2007. The flagship AEMES initiative, the AEMES Scholars program, was crafted to target URM and/or first-generation college students, particularly from low-income families. The goal of the AEMES Scholars program was to foster inclusive excellence for diverse women in the sciences, especially early in their time at college, inspired by and modeled on university programs found effective for improving outcomes for underrepresented students in the sciences (e.g., Matsui et al., 2003; Summers and Hrabowski, 2006). One central feature of the AEMES Scholars program is a faculty-mentored research experience for underrepresented students who aspire to major in STEM. The benefits of undergraduate research experiences to STEM success are well established (Nagda et al., 1998; Russell et al., 2007), with recent calls for early research involvement to address problems of underrepresentation in the field (PCAST, 2012; Graham et al., 2013). The AEMES Scholars program was administered within a cohort model and delivered additional program elements that foster social and academic integration in the college setting (Tinto, 1993; National Academy of Sciences, National Academy of Engineering, and Institute of Medicine, 2011), including peer mentoring, community-building events, and a skill-building seminar. The AEMES program components are acknowledged as empirically based approaches to persistence (National Academy of Sciences, National Academy of Engineering, and Institute of Medicine, 2011; Graham et al., 2013) and were administered during the first 2 years in college, an important time for fostering student success (Hurtado and Carter, 1997).

Consistent with the recommendations of the National Academy of Sciences, National Academy of Engineering, and Institute of Medicine (2011), the current paper describes two essential pieces of program building-program evaluation and knowledge sharing - that can contribute to the literature on addressing issues of STEM persistence, in this case, for women in a liberal arts setting. Analyzing academic record data, this paper examines AEMES Scholars' outcomes over time, comparing them with those of underrepresented students before program launch and to relevant peer comparison groups.

\section{METHODS \\ Program Description}

AEMES Scholars received a rich array of resources during their first 2 years of college, although arguably the most central was the opportunity (and accompanying stipend) they received to be mentored by and work with a faculty member on research. Faculty research mentors met weekly with their AEMES Scholars and typically served as the students' academic advisors. In 
the Fall of their first year, Scholars were also matched with a peer mentor who was a returning science major. ${ }^{1}$ Mentors and mentees were expected to be in contact weekly and met once a month in person. In addition, community building was fostered within and across AEMES Scholars' cohorts through a variety of social and cohort-building events and through a skill-building seminar on applied learning strategies that included peer studygroup work, taken by all Scholars in the Fall of their first year. One goal of the AEMES Scholars program was to create a cohort of students who could serve as role models in our science community. To help accomplish this goal, we hold an annual AEMES research symposium in which a subset of Scholars present their research projects in front of a wide audience, including college administrators, faculty, staff, fellow students, and members of the board of trustees.

\section{AEMES Scholar Selection}

Every year since 2007, approximately 20 AEMES Scholars have been chosen from admitted students. Recruitment of AEMES Scholars from our admitted student pool each Spring targeted domestic students from groups underrepresented in STEM. Scholars indicated an interest in STEM (i.e., through some explicit science interest articulated in the application, e.g., in the essay; first-choice prospective major indicated in the admissions' application was a STEM field) and were recruited from within the middle range (3 through 6) of Smith's holistic admissions' reader rating scores. ${ }^{2}$

\section{Program Evaluation Group Selections and Data Analytic Approach}

Because the AEMES Scholars program is targeted at a limited group of students, we developed comparison groups of nonAEMES students who met the AEMES selection criteria of domestic student status and middle-range admission scores. ${ }^{3}$ Students who did not meet AEMES Scholars' selection criteria (i.e., domestic student; midrange admission scores) were excluded from all analyses. ${ }^{4}$ The remaining domestic students

\footnotetext{
${ }^{1}$ Peer mentoring is provided automatically for all AEMES Scholars. It is also available to any science student who expresses an interest.

${ }^{2}$ Reader ratings range from 1 (most competitive applicants) to 10 (least competitive applicants) based on a holistic assessment of student's college preparedness determined by: transcript analysis of high school course rigor, class standing, and GPA; strength of teacher recommendations; evaluation of personal essay; and participation in leadership opportunities and extracurricular activities. Smith College became Scholastic Aptitude Test (SAT) test optional in 2008. Even before the college became SAT optional, standardized test scores (SAT, ACT) were weighted least heavily in reader ratings relative to the other inputs described above; this remains true today when scores are submitted. Reader ratings are calibrated through a process in which every application is read and rated by at least two faculty or admissions officer readers, with disagreements resolved through consensus coding and/or pulling in additional readers. Students with the highest reader ratings are eligible for a different college-wide scholarship program through our Student Research in Departments (STRIDE) program, which provides a generous 4-year scholarship and a 2-year paid research assistantship to each recipient.

${ }^{3}$ There were no significant differences in admissions' reader ratings scores across groups either pre- or post-AEMES.

${ }^{4}$ In the program's early phases, a handful of students outside the target criteria were included in the AEMES Scholars program, including one international student and eight students whose admission ratings fell outside the middle range (both above and below); these nine students were excluded from the intervention group analysis.
}

with midrange admission scores were segmented into groups that participated in AEMES and comparison groups who did not. Analyses were further segmented by whether students entered Smith before or after the inception of the AEMES program and whether they are identified as belonging to an underrepresented population (see below and Figure 1 for details).

The central focus of this paper was to evaluate the AEMES Scholars program using academic record data. We limited the AEMES Scholars included in this evaluation to those who belonged to at least one of three categories: URM (defined as African American, Latina, or Native American); first-generation college student (defined as coming from families in which neither parent attained a 4-year degree); or Pell grant recipient (as a proxy for students from low-income backgrounds). A total of 28 Scholars were excluded from this analysis based on these criteria, ${ }^{5}$ leaving a total of 105 AEMES Scholars included in this program evaluation. Sixty percent of Scholars fell into two or more of these groups (see Figure 2).

First, we compared data for our selected AEMES Scholars with those of two peer groups: students who belonged to a STEM-underrepresented group (one of more of the following categories: URM; first-generation status student; Pell grant recipient) but were not part of the AEMES Scholars program (called our "underrepresented population students, not AEMES Scholars" for the purposes of this paper); and students who did not fall into any of the three categories of STEM underrepresentation targeted by our AEMES programs (called "well-represented population students" for the purposes of this paper).

Second, we compared AEMES Scholars' outcomes with those of a comparative baseline group (i.e., underrepresented students before the AEMES programs launched) to examine changes over time. Because our measure of advanced research participation is defined as participation in credit-bearing research opportunities in the junior and/or senior year, analyses involving this measure were limited to alumnae, excluding currently enrolled students who had not yet completed their final year at the college. Analyses for gateway course GPA and persistence measures combined alumnae with currently enrolled students.

For measures of persistence as well as advanced research participation, we compared groups in life sciences (i.e., chemistry, neuroscience, biochemistry, and biological sciences) specifically and in the natural sciences overall (i.e., the groups above plus physics, engineering, astronomy, geosciences, psychology, computer science, and mathematics and statistics).

\section{RESULTS}

\section{Demographic and SAT Data}

Demographic data describing our AEMES Scholars (see also Figure 2) and our underrepresented population students who did not participate in the AEMES Scholars program over the

\footnotetext{
${ }^{5}$ The 28 AEMES Scholars who were excluded were Asian-American students who were neither first-generation students nor Pell grant recipients. These students were originally recruited for the AEMES program based on early analyses indicating a gap between Asian-American versus other students on rates of on-campus summer research fellowship participation. More recent analyses find that our Asian-American students who are neither first-generation nor Pell grant recipients evidence academic outcomes, including on each of the measures included in this program evaluation, that are comparable to or even better than similar comparison students.
} 


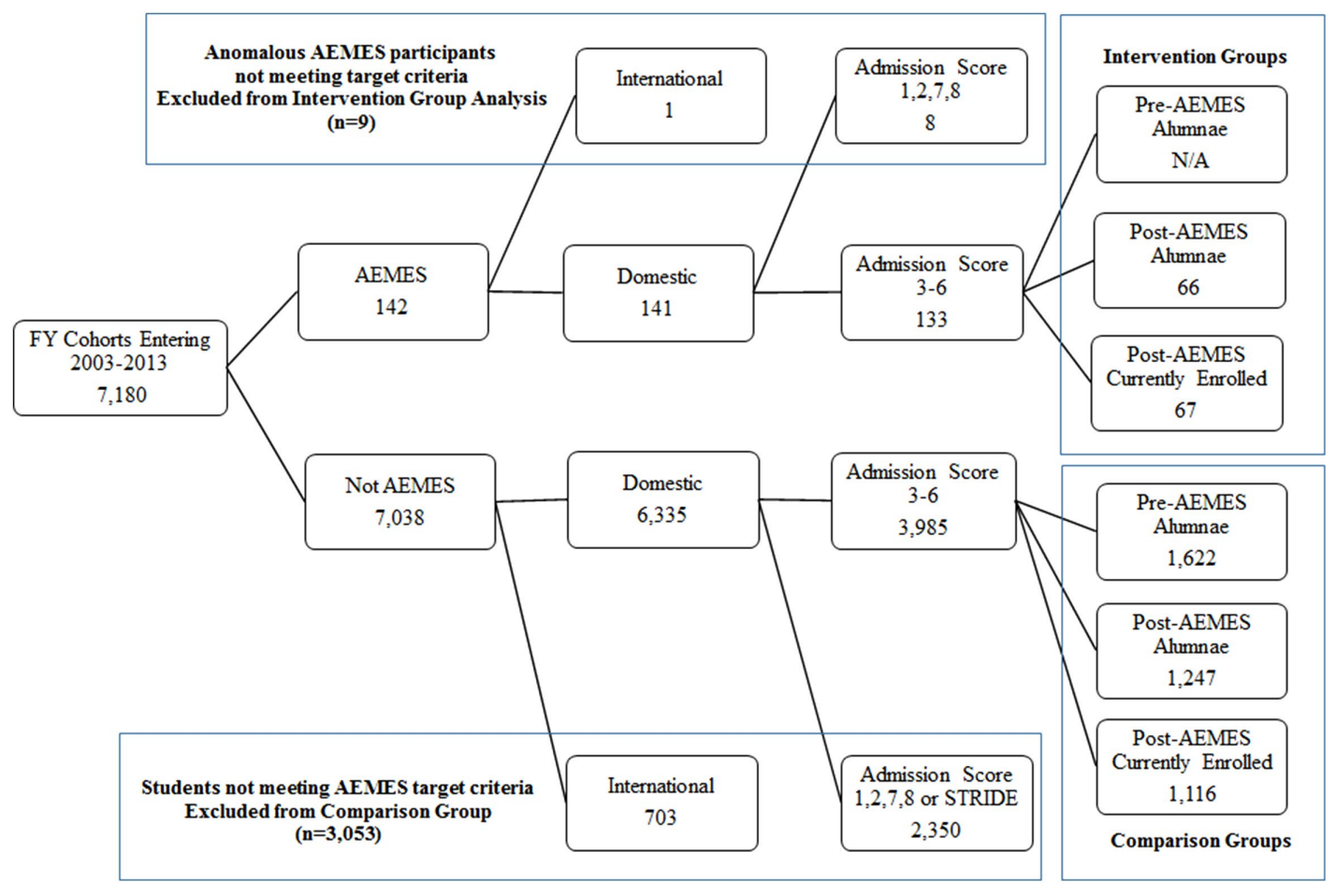

FIGURE 1. Overview of group selections for program evaluation.

years 2007-2014 are provided in Table 1 . We provide average SAT math and SAT combined math and verbal scores for our three comparison groups from before to after AEMES' launch in Table $2 .^{6}$

Underrepresented students admitted to Smith had significantly lower SAT math scores in comparison with their wellrepresented population peers before AEMES launch, although their combined SAT scores were not significantly different. More recently (since Smith adopted an SAT-optional policy), AEMES Scholars matriculated with math and combined SAT scores that were not significantly different from their underrepresented, non-AEMES Scholar counterparts. For SAT combined scores, both groups have scores that are significantly lower than their well-represented peers, whereas for SAT math scores, this is only true for underrepresented non-AEMES Scholars. No SAT scores significantly increased for AEMES Scholars relative to baseline; however, SAT total scores rose for underrepresented students who were not AEMES Scholars, as did both SAT total and math scores for well-represented students.

\section{GPA in Gateway Biology and Chemistry Courses}

Before AEMES' launch, our STEM-underrepresented students had GPAs in introductory biology and chemistry gateway courses ${ }^{7}$ that were significantly lower than their well-represented peers.

${ }^{6}$ As noted earlier, Smith College went test optional in 2008. Rates of nonreporting of SAT scores significantly increased for each group from before to after AEMES launch. There were, however, no significant differences in the rate of reported SAT scores across groups at either time point.

${ }^{7}$ Gateway biology and chemistry courses were defined as the core courses within each discipline for its major, ordinarily taken in the first 2 years of college (three semesters of biology and four semesters of chemistry-two of general chemistry and two of organic chemistry).
Since AEMES, overall gateway GPA has significantly increased for every group of students. Post-AEMES, students in our Scholars program no longer evidence a gap in GPA in gateway courses relative to well-represented students (see Table 3). STEM-underrepresented students who were not AEMES Scholars also demonstrated a significant GPA increase over

\section{Underrepresented Populations Among AEMES Scholars}

$$
(\mathrm{N}=\mathbf{1 0 5})
$$

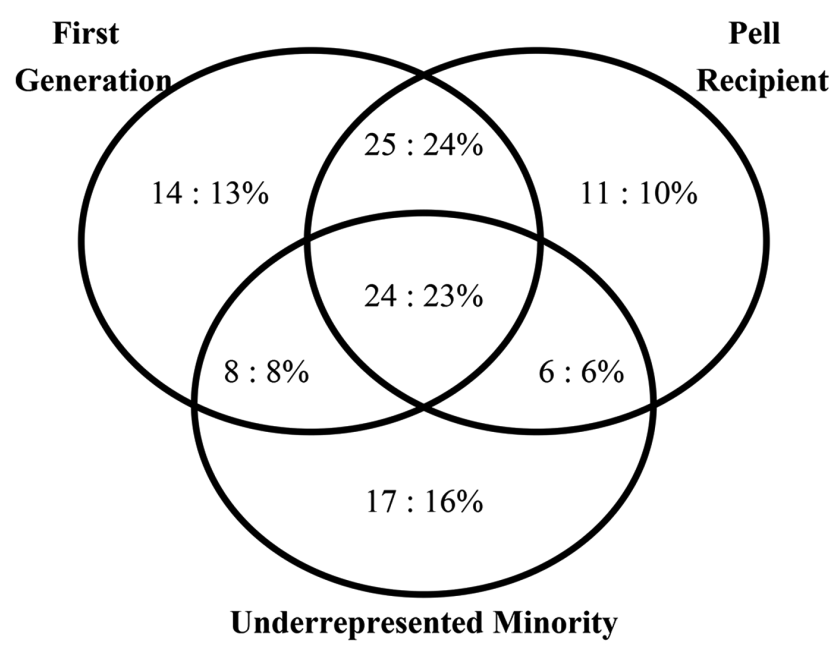

Note: There were 28 AEMES Scholars who were Asian-American students who were neither first-generation students nor Pell Grant recipients. They are not included in the percentages.

FIGURE 2. Numbers: percentages of Scholars reporting the demographic factors related to science underrepresentation targeted by the AEMES programs. 
TABLE 1. Demographic data for first-year students from 2007-2014

\begin{tabular}{lcccc}
\hline & Total number & URM & First-generation status & Pell grant recipient \\
\hline AEMES Scholars & 105 & $50.5 \%$ & $67.6 \%$ & $62.9 \%$ \\
Underrepresented population students, not AEMES Scholars & 722 & $31.9 \%$ & $49.2 \%$ & $63.3 \%$ \\
Smith College students, overall & 4583 & $16.7 \%$ & $17.2 \%$ & $17.5 \%$ \\
\hline
\end{tabular}

a URM includes African-American, Latina, and Native American students. First-generation students include students coming from families in which neither parent attained a 4-year degree.

TABLE 2. Incoming academic characteristics across comparison groups from before to after the launch of AEMES programming ${ }^{\mathrm{a}}$

\begin{tabular}{|c|c|c|c|c|}
\hline & & AEMES Scholars & $\begin{array}{l}\text { Underrepresented population } \\
\text { students, not AEMES Scholars }\end{array}$ & Well-represented population students \\
\hline \multirow[t]{8}{*}{ SAT total } & Pre-AEMES students & & $1211^{1}$ & $1289^{2}$ \\
\hline & & & $\mathrm{SD}=137$ & $\mathrm{SD}=105$ \\
\hline & & & $N=526$ & $N=1014$ \\
\hline & & & $5 \%$ not reported & $5 \%$ not reported \\
\hline & Post-AEMES students & $1210^{\mathrm{A}}$ & $1243^{\mathrm{B}, 1}$ & $1312^{\mathrm{A}, \mathrm{B}, 2}$ \\
\hline & & $\mathrm{SD}=120$ & $\mathrm{SD}=124$ & $\mathrm{SD}=110$ \\
\hline & & $N=69$ & $N=511$ & $N=1214$ \\
\hline & & $34 \%$ not reported & $29 \%$ not reported & $26 \%$ not reported \\
\hline \multirow[t]{8}{*}{ SAT math } & Pre-AEMES students & & $597^{\mathrm{A}}$ & $624^{\mathrm{A}, 1}$ \\
\hline & & & $\mathrm{SD}=72$ & $\mathrm{SD}=65$ \\
\hline & & & $N=526$ & $N=1014$ \\
\hline & & & $5 \%$ not reported & $5 \%$ not reported \\
\hline & Post-AEMES students & 618 & $604^{\mathrm{B}}$ & $632^{\mathrm{B}, 1}$ \\
\hline & & $\mathrm{SD}=74$ & $\mathrm{SD}=72$ & $\mathrm{SD}=68$ \\
\hline & & $N=69$ & $N=511$ & $N=1214$ \\
\hline & & $34 \%$ not reported & $29 \%$ not reported & $26 \%$ not reported \\
\hline
\end{tabular}

${ }^{a}$ Smith College became test optional in 2008. Only SAT scores were used in analysis. There were no significant differences in rates of nonreporting of SAT scores across post-AEMES groups. Between-group comparisons were analyzed within each dependent variable separately. Results are based on the post hoc Tukey's honest significant difference (HSD) test for multiple comparisons of means using a 95\% family-wise confidence level. Paired letters/numbers note significant difference $(p$ value $<0.05$; $q>3.90 ; d f>120$ ) across groups within each time (using lettered superscripts) as well as within a specific group across time (using numbered superscripts).

time. The gap between these students and well-represented population students, although statistically significant, has shrunk considerably (from a gap of 0.23 to a current gap of 0.12 over time) and the non-AEMES Scholars' GPA is almost identical to that of AEMES Scholars who are not statistically different from their well-represented peers. ${ }^{8}$

\section{STEM Persistence Rates}

For this analysis, a student's intended major as indicated at the time of admission was compared with her actual major, declared by Spring of her sophomore year (see Table 4). Before AEMES' launch, there were no observed differences in persistence rates across underrepresented versus well-represented students for either life or natural sciences majors.

Life Sciences Majors. AEMES Scholars who were interested in the life sciences at matriculation persisted in those majors at significantly higher rates than underrepresented students with the same interests before the program's launch (rising from 47.9 to 73.1\%), a rate that is now almost two times higher than their comparable STEM-underrepresented peers (37.5\%). AEMES

${ }^{8}$ We also examined gateway course GPA outcomes with each individual student as the unit of analysis, using a generalized estimating equation, to account for multiple courses taken by a single student. We found the same pattern of results.
Scholars' persistence rates exceeded their well-represented peers' rates $(60.9 \%)$, although this result was not statistically significant. There now exists a significant gap in life sciences persistence between STEM-underrepresented students who were not AEMES Scholars relative to their well-represented peers.

Natural Sciences Majors Overall. Persistence rates for students interested in a natural sciences major significantly increased overall since the start of the AEMES programs. AEMES Scholars showed a significant increase in persistence in the natural sciences over time relative to baseline (rising to 88.4 from $69.8 \%$ ), with a rate that is now significantly higher than persistence for our well-represented students (70.4\%) as well as other STEM-underrepresented students who were not AEMES Scholars (64.6\%). These latter two groups' rates of persistence are not significantly different from one another and have stayed stable over time.

\section{Participation in Advanced Scientific Research}

We examined participation in credit-bearing scientific facultymentored research opportunities through honors or independent research in students' junior or senior years across groups (see Table 5). At AEMES' start, there were no significant differences across groups in either life or natural sciences research participation. 
TABLE 3. Biology and chemistry gateway course GPA across comparison groups from before to after the launch of AEMES programming ${ }^{\mathrm{a}}$

\begin{tabular}{|c|c|c|c|c|}
\hline & AEMES Scholars ${ }^{\mathrm{b}}$ & $\begin{array}{l}\text { Underrepresented population students, } \\
\text { not AEMES Scholars }\end{array}$ & $\begin{array}{l}\text { Well-represented } \\
\text { population students }\end{array}$ & Total students \\
\hline \multirow[t]{2}{*}{ Pre-AEMES launch } & & $2.77^{\mathrm{A}, 1,2}$ & $3.00^{\mathrm{A}, 3}$ & $2.91^{4}$ \\
\hline & & $N=619$ & $N=894$ & $N=1513$ \\
\hline \multirow[t]{2}{*}{ Post-AEMES launch } & $2.99^{1}$ & $2.97^{\mathrm{B}, 2}$ & $3.09^{\mathrm{B}, 3}$ & $3.00^{4}$ \\
\hline & $N=349$ & $N=966$ & $N=2087$ & $N=3402$ \\
\hline
\end{tabular}

aPA is on a 4.0 scale. $N$ values here represent the total number of course grades within each group. Between-group comparisons were analyzed within each dependent variable separately. Results are based on the post hoc Tukey's HSD test for multiple comparisons of means using a 95\% family-wise confidence level. Paired letters/ numbers note significant difference ( $p$ value $<0.05 ; q>3.90 ; d f>120$ ) across groups within each time (using lettered superscripts) as well as within a specific group across time (using numbered superscripts).

'The AEMES Scholar group combines all students enrolled in AEMES from 2007 to 2013, including both students who are now alumnae and currently enrolled students.

TABLE 4: Persistence in science across comparison groups from before to after the launch of AEMES programming ${ }^{\text {a }}$

\begin{tabular}{|c|c|c|c|c|c|}
\hline & & AEMES Scholars ${ }^{\mathrm{b}}$ & $\begin{array}{l}\text { Underrepresented population } \\
\text { students, not AEMES Scholars }\end{array}$ & $\begin{array}{c}\text { Well-represented } \\
\text { population students }\end{array}$ & Total students \\
\hline \multirow[t]{4}{*}{ Life sciences } & Pre-AEMES & & $47.9 \%^{1}$ & $57.5 \%$ & $53.7 \%$ \\
\hline & & & $N=48$ & $N=73$ & $N=121$ \\
\hline & Post-AEMES & $73.1 \%{ }^{\mathrm{A}, 1}$ & $37.5 \% \%^{\mathrm{A}, \mathrm{B}}$ & $60.9 \%^{\mathrm{B}}$ & $61.3 \%$ \\
\hline & & $N=52$ & $N=24$ & $N=110$ & $N=186$ \\
\hline \multirow[t]{4}{*}{ Natural sciences } & Pre-AEMES & & $69.8 \%{ }^{1}$ & $62.3 \%$ & $65.4 \%^{2}$ \\
\hline & & & $N=149$ & $N=204$ & $N=353$ \\
\hline & Post-AEMES & $88.4 \% \%^{\mathrm{A}, \mathrm{B}, 1}$ & $64.6 \%{ }^{\mathrm{A}}$ & $70.4 \%^{\mathrm{B}}$ & $72.3 \%{ }^{2}$ \\
\hline & & $N=86$ & $N=113$ & $N=270$ & $N=469$ \\
\hline
\end{tabular}

aPersistence in science is defined as a match between intended major as reported at time of admission and declared major (with the top of the table focused on persistence in life sciences for those who declared an intention to major in one of the life sciences and the bottom of the table focused on persistence in the natural sciences for those who declared an intention to major in any of the natural sciences). Between-group comparisons were analyzed within natural sciences or life sciences. Results are based on pairwise two-sided Pearson chi-square tests. Paired letters/numbers note significant differences ( $p$ value $\left.<0.05 ; \chi^{2}>3.841 ; d f=1\right)$ across groups within each time (using lettered superscripts) as well as within a specific group across time (using numbered superscripts).

'The AEMES Scholar group combines all students enrolled in AEMES from 2007 to 2013, including both students who are now alumnae and currently enrolled students.

Life Sciences Majors. There were no significant differences across groups over time. Currently, $61.0 \%$ of our life sciences students overall participate in these research opportunities before graduation.

Natural Sciences Majors Overall. Rates of advanced research significantly increased overall for natural sciences students since AEMES' launch, although comparisons across groups reveals that this significant increase was only true for AEMES Scholars (43.6 to 63.6\%) and well-represented (42.2 to 54.8\%) students. Students from each of these groups had significantly higher rates of advanced natural sciences research participation than other STEM-underrepresented students (43.6 to $41.7 \%$ ), who showed no increases over time.

\section{DISCUSSION}

The AEMES programs were designed to foster inclusive excellence for underrepresented women interested in STEM, using a cohort model with a particular focus on faculty research mentorship during the early years of college. Data on student outcomes since the launch of AEMES indicate a number of gains for AEMES Scholars over time relative to underrepresented

TABLE 5: Advanced research participation across comparison groups from before to after the launch of AEMES programminga

\begin{tabular}{|c|c|c|c|c|c|}
\hline & & AEMES Scholars ${ }^{\mathrm{b}}$ & $\begin{array}{l}\text { Underrepresented population } \\
\text { students, not AEMES Scholars }\end{array}$ & $\begin{array}{l}\text { Well-represented } \\
\text { population students }\end{array}$ & Total students \\
\hline \multirow[t]{4}{*}{ Life sciences } & Pre-AEMES & & $53.5 \%$ & $51.3 \%$ & $52.1 \%$ \\
\hline & & & $N=71$ & $N=117$ & $N=188$ \\
\hline & Post-AEMES & $69.2 \%$ & $53.8 \%$ & $61.6 \%$ & $61.0 \%$ \\
\hline & & $N=26$ & $N=39$ & $N=99$ & $N=164$ \\
\hline \multirow[t]{4}{*}{ Natural sciences } & Pre-AEMES & & $43.6 \%{ }^{1}$ & $42.2 \%^{2}$ & $42.7 \% \%^{3}$ \\
\hline & & & $N=179$ & $N=268$ & $N=447$ \\
\hline & Post-AEMES & $63.6 \%{ }^{\mathrm{A}, 1}$ & $41.7 \% \%^{\mathrm{A}, \mathrm{B}}$ & $54.8 \%{ }^{\mathrm{B}}$ & $52.3 \%^{3}$ \\
\hline & & $N=44$ & $N=108$ & $N=259$ & $N=411$ \\
\hline
\end{tabular}

advanced research participation is defined as participation in credit-bearing, scientific faculty-mentored research opportunities available within the major through honors or independent research in the junior or senior year. Between-group comparisons were analyzed within natural sciences or life sciences. Results are based on pairwise two-sided Pearson chi-square tests. Paired letters/numbers note significant differences ( $p$ value $<0.05 ; \chi^{2}>3.841 ; d f=1$ ) across groups within each time (using lettered superscripts) as well as within a specific group across time (using numbered superscripts).

'The AEMES Scholar group includes only AEMES students who have graduated. 
students at baseline, including significantly higher gateway course GPA, rates of persistence in both life and natural sciences, and participation in natural sciences research over time. More recently, AEMES Scholars had equivalent outcomes relative to their well-represented population student peers on just about every measure. These findings are consistent with the broader scientific literature that acknowledges the critical role of early research in fostering persistence and success in STEM (Nagda et al., 1998; Graham et al., 2013; DiBartolo et al., 2016).

At Smith, more students than ever are seeking opportunities for authentic scientific research, and our observation is that intrepid students who successfully secure access to these opportunities are those who have the social capital to seek and land a lab spot, understanding the important role research experience plays in STEM success after graduation. Not surprisingly, well-represented students appear able to navigate this process fairly well on their own; our data show an increase in their advanced research participation in the natural sciences since the launch of AEMES, with the majority of them (54.8\%) completing at least one such experience even without early research mentorship. In comparison, our underrepresented students who are non-Scholars are less likely to complete advanced research than their peers (41.7\%), whereas $63.6 \%$ of our AEMES Scholars participate in research. Providing our AEMES Scholars with faculty mentorship through a research experience in the first 2 years of college appears to provide underrepresented women level access to advanced research relative to their well-represented peers and better access relative to their underrepresented non-Scholars peers.

Not surprisingly, our data also show evidence of a connection between participation in the AEMES program and later student persistence in STEM major. For students who entered Smith with an intention of majoring in a STEM field, AEMES Scholars continued on with a major in STEM at significantly higher rates than all other students. Although rates of persistence in the natural sciences were generally high for all three groups, exceeding national averages (HERI, 2010), one concerning finding was the relatively low rate of persistence in life sciences for STEM-underrepresented students who were not AEMES Scholars. Their persistence rate of $37.5 \%$ was almost half of what their AEMES Scholars peers reached (73.1\%). Despite this concerning finding, we would note that there is no gap for persistence in natural sciences (STEM major overall) for our underrepresented population, non-AEMES Scholars relative to their well-represented peers. These students are not leaving STEM fields overall; they are just not persisting in life sciences specifically when they have stated an intention to do so. Although some of the life sciences analyses are limited by the small number of students in certain comparison subgroups, this rate is one that we are actively addressing through both faculty development and AEMES program extensions.

One important additional change since the launch of AEMES is that Scholars' gains in gateway course GPA dissolved the gap that existed between STEM-underrepresented and well-represented students. The gap is now minimal (0.12 on a 4-point scale), although still statistically significant, for our underrepresented students who were not AEMES Scholars. Over this same period of time, faculty have invested in broad efforts to shift curricula and pedagogies toward approaches that promote access and persistence for all students. Across departments, the faculty intensified its focus on student-centered and active pedagogies, especially at the introductory level of our curriculum. Research indicates that these approaches have demonstrable effects on class performance and rates of persistence for all students (Graham et al., 2013; Freeman et al., 2014), working particularly well for underrepresented students (Eddy and Hogan, 2014). All of our students now average grades of about a "B" in our gateway courses in biology and chemistry, indicating that we have made some meaningful progress in ensuring the equivalent likelihood of success for our students in this part of our curriculum, with a slight advantage to our AEMES Scholars relative to our underrepresented students who were not AEMES Scholars.

Overall, the AEMES Scholar program evaluation suggests that an early research component may help foster the interest and success of underrepresented women in STEM, as measured by gateway course GPA, choice of STEM major, and advanced research participation in the later years of college. There are still many questions that need answers. First, we need to understand more fully what aspects or mechanisms of the Scholars program account for its positive effects. It may well be that the work the Scholars did in research labs along with the other AEMES programming elements (e.g., peer mentoring, learning strategies seminar) helped to boost their skills and self-concept in STEM over time, consolidating their confidence in a broad range of learning opportunities. As one Scholar put it,

So having that advantage of having worked in the lab and having someone explain it to me, and ... not even just being introduced to the lab but acquiring these really great lab skills right away has really helped me in classes, and my self esteem, so all sorts of cool things.

The increase in one-on-one academic advising provided through this research model is another possible benefit, as is the increased interaction of first-year students with juniors and seniors who also participate in research groups. Understanding these mechanisms is a critical next step and one we are further exploring.

Future research would do well to incorporate measures beyond those included here to determine how variables like intent, interest, and motivation for STEM study affect academic outcomes in similar program evaluations. Although the incoming characteristics we were able to examine for the underrepresented students who were selected versus not for the AEMES Scholars program were equivalent (i.e., no significant differences for these two groups on reader rating, SAT math, or SAT combined scores), there may be other ways in which Scholars started with an advantage, such as their motivation for and interest and/or prior success in STEM study. These confounds could differ across cohorts and interact with our programs. Ideally, future studies might use randomized controlled research designs to even more rigorously test similar program impacts in order to eliminate the influence of these and other potential confounding variables.

We also need to understand what accounted for improvements for non-AEMES students over time. As previously noted, we have expanded efforts to provide best-practices pedagogies. Faculty and staff are also expanding efforts toward inclusive 
excellence by integrating research opportunities using coursebased research experiences throughout our curriculum, especially at the introductory level, in part because faculty mentors of AEMES Scholars have witnessed the power of early research in shaping our underrepresented students' sense of academic integration (cf. Nettles et al., 1986; Tinto, 1993) and identity as scientists while setting them on a trajectory for continued persistence and success (cf. Graham et al., 2013). By scaling up the research training and mentorship that define the AEMES Scholars program to make them broadly accessible, we hope to draw underrepresented students in particular to STEM study. We have also more recently (2010-2011) launched two additional programs under the AEMES umbrella to reduce barriers to participation in STEM for our students. The Early Research program pairs first- and second-year students as volunteer research assistants with faculty, thereby giving students outside the AEMES Scholars program access to early research experiences. The McKinley Fellowship program enables a small number of eligible juniors and seniors to complete their work-study requirement within the lab where they are pursuing research, allowing students who have a substantial work-study requirement to carve out the time needed for intensive research. Our AEMES Peer Mentoring program is also open to all STEM students at the college, given the positive influence of these kinds of initiatives on academic outcomes (cf. Packard, 2016).

Over time, our AEMES programs have helped to drive institutional shifts and investments, creating a groundswell of support for expanded opportunities that advance inclusive excellence using approaches that foster student success in multiple ways. The social transformation theory of change asserts that institutional change is both a process and an outcome of programs that support diversity in higher education (Maton et al., 2008, 2012). As Scholars have gone on to extraordinary success in our classrooms and laboratories, they have helped to empower similar students and shifted our community's commitment to inclusive excellence. Other contextual developments at our institution have supported and expanded the impact of the AEMES programs, including articulation of access as central to the mission of the college and our science division and sustained efforts of a team of faculty and staff to understand and address barriers to access in the sciences.

Overall, these data provide evidence of the efficacy of the AEMES Scholars program to advance inclusive excellence for underrepresented women in STEM. One of the first program evaluations focused on STEM access at a women's college, analysis of the AEMES Scholars program extends the literature on the power of early research and suggests that underrepresented women can demonstrably benefit from institutional investments in programming that foster research skills and connect students to faculty mentors. The study has a number of strengths, including its peer comparison groups, objective measures of academic outcomes, and focus on issues of persistence for underrepresented women interested in STEM. Almost two-thirds of our Scholars fell into two or more categories that put them at risk for underperformance in STEM outcomes (cf. Chen and Carroll, 2005; Anderson and Kim, 2006), yet their outcomes were quite positive. This evaluation does have some limitations, however, including its overall relatively small sample size; the challenge of identifying an appropriate comparison group; multiple statistical comparisons, including some focused on small cell sizes; and ongoing modifications to admissions policy and curriculum and persistence programming at the same time as the implementation of the Scholars program. As noted earlier, it is possible that incoming and/or unmeasured differences (attitudinal, motivational, skills based) for our AEMES Scholars versus other student groups (or the interaction of these kinds of participant characteristics and our programming) might help account for some differences in outcomes. As a result, our findings should be considered exploratory, and we will continue to monitor program outcomes over time.

The goals of the AEMES programming writ large are consistent with the principles of fostering persistence in STEM students (cf. Maton et al., 2012; Graham et al., 2013). Nonetheless, given our data, we see the need for additional work creating opportunities and shifting institutional culture for all of our students. We are currently working to evaluate and expand each AEMES component so that we can hone our programming and understand outcomes across the intersectional identities (race/ethnicity, gender, socioeconomic status) that define today's STEM students. We are also working to collect continuous and varied measures of AEMES Scholar outcomes, including postgraduation trajectories and qualitative data on lived experiences and potential mediators of the AEMES programs impacts.

We believe that the insights from our programs can be applicable to other institutions, providing additional evidence of the power of early research to shape underrepresented students' educational trajectories across a range of institutions with different missions (ranging from big research universities to small liberal arts colleges). Women's colleges in particular may consider investing in the development of an AEMES-like program that can foster the success of students across STEM fields, wherein gender and other forms of underrepresentation are problematic. At Smith, we will continue to engage in thoughtful and data-driven reflection and assessment that allows us to build sustainable and structural changes that help to address underrepresentation. Such investments can contribute to the diversification of STEM fields and allow us to reap the benefits of a broader set of approaches and perspectives (Hong and Page, 2004).

\section{ACKNOWLEDGMENTS}

The AEMES programs have been generously supported by Janet Clarke McKinley '76, through the McKinley Fund of Smith College, with additional support from the HHMI's Undergraduate and Graduate Science Education Program, Exelon, the William Randolph Hearst Foundations, and the special grant program of the Camille and Henry Dreyfus Foundation. Thanks to Deb Shaver, Martha Miller, and Yadira Flores for assistance with preparation of the article and to Katie Lipp and Valerie Joseph for their work in overseeing program administration. Portions of this paper were presented at the HHMI Studio meeting, held in Chevy Chase, MD, in June 2015, and at the AACU/Project Kaleidoscope meeting, held in Seattle, WA, in November 2015.

\section{REFERENCES}

American Association of Colleges and Universities (2015). Committing to Equity and Inclusive Excellence: A Campus Guide for Self-Study and Planning, Washington, DC. 
Anderson E, Kim D (2006). Increasing Success of Minority Students in Science and Technology, Washington, DC: American Council on Education.

Aronson P (2008). Breaking barriers or locked out? Class-based perceptions and experiences of postsecondary education. In: Social Class and Transitions to Adulthood, ed. JT Mortimer, New Directions for Child and Adolescent Development 119, 41-54

Chen X, Carroll CD (2005). First-Generation Students in Postsecondary Education: A Look at Their College Transcripts (NCES 2005-171,), Washington, DC: National Center for Education Statistics, U.S. Department of Education. http://nces.ed.gov/pubs2005/2005171.pdf (accessed 28 December 2015).

DiBartolo PM, Gregg-Jolly L, Gross D, Manduca CA, Iverson E, Cooke DB, Davis GK, Davidson C, Hertz PE, Hibbard L, et al. (2016). Principles and practices fostering inclusive excellence: lessons from the Howard Hughes Medical Institute's Capstone Institutions. CBE Life Sci Educ 15, ar44.

Eddy SL, Hogan KA (2014). Getting under the hood: how and for whom does increasing course structure work? CBE Life Sci Educ 13, 453-468.

Freeman RB, Huang W (2014). Strength in diversity. Nature 513, 305

Freeman RB, Huang W (2015). Collaborating with people like me: ethnic coauthorship within the United States. J Labor Econ 33, S289-S318.

Freeman S, Eddy SL, McDonough M, Smith MK, Okoroafor N, Jordt H, Wenderoth MP (2014). Active learning increases student performance in science, engineering, and mathematics. Proc Natl Acad Sci USA 111, 8410-8415.

Graham MJ, Frederick J, Byars-Winston A, Hunter AB, Handelsman J (2013). Increasing persistence of college students in STEM. Science 341, 14551456.

Higher Education Research Institute (2010, January). Degrees of Success: Bachelor's Degree Completion Rates among Initial STEM Majors, HERI Research Brief, Los Angeles: University of California, Los Angeles. www.heri ucla.edu/nih/downloads/2010\%20 - \%20 Hurtado,\%20Eagan,\%20 Chang\%20-\%20Degrees\%20of\%20Success.pdf (accessed 6 January 2016).

Hill C, Corbett C, St. Rose A (2010). Why So Few? Women in Science, Technology, Engineering, and Mathematics, Washington, DC: AAUW.

Hong L, Page SE (2004). Groups of diverse problem solvers can outperform groups of high-ability problem solvers. Proc Natl Acad Sci USA 101, 16385-16389.

Howard Hughes Medical Institute (2007, February). Diversifying science. HHMI Bull 12-13, 56

Hurtado S, Carter DF (1997). Effects of college transition and perceptions of campus racial climate on Latino college students' sense of belonging. Sociol Educ 70, 324-345.

Leggon CB (2010). Diversifying science and engineering faculties: intersections of race, ethnicity, and gender. Am Behav Sci 53, 1013-1028.

Maton KI, Hrabowski FA, Ozdemir M, Wimms H (2008). Enhancing representation, retention, and achievement of minority students in higher education: a social transformation theory of change. In: Toward Positive Youth Development: Transforming Schools and Community
Programs, ed. M Shinn and H Yoshikawa, New York: Oxford University Press, 115-133.

Maton KI, Pollard SA, Weise TVM, Hrabowski FA (2012). The Meyerhoff Scholars program: a strengths-based, institution-wide approach to increasing diversity in science, technology, engineering, and mathematics. Mt Sinai J Med 79, 610-623

Matsui J, Liu R, Kane CM (2003). Evaluating a science diversity program at UC Berkeley: more questions than answers. Cell Biol Educ 2, 117-121.

Nagda BA, Gregerman SR, Jonides J, von Hippel W, Lerner JS (1998). Undergraduate student-faculty research partnerships affect student retention Rev High Educ 22, 55-72.

National Academy of Sciences, National Academy of Engineering, and Institute of Medicine (2011). Expanding Underrepresented Minority Participation: America's Science and Technology Talent at the Crossroads, Washington, DC: National Academies Press. https://grants.nih.gov/training/ minority_participation.pdf (accessed 30 December 2015).

National Science Board (2014). Science and Engineering Indicators (NSB 14 01), Arlington, VA: National Science Foundation. www.nsf.gov/statistics/ seind14/index.cfm/chapter-2\#s2 (accessed 29 December 2015).

National Science Foundation (2015). National Center for Science and Engineering Statistics, IPEDS Completion Survey. https://ncsesdata.nsf.gov/ webcaspar (accessed 3 November 2015)

Nettles MT, Thoeny AR, Gosman J (1986). Comparative and predictive analyses of Black and White student's college achievement and experiences. J High Educ 57, 289-318.

Packard BW (2016). Successful STEM Mentoring Initiatives for Underrepresented Students: A Research-Based Guide for Faculty and Administrators, Sterling, VA: Stylus.

President's Council of Advisors on Science and Technology (2012). Engage to Excel: Producing One Million Additional College Graduates with Degrees in Science, Technology, Engineering, and Mathematics, Washington, DC U.S. Government Office of Science and Technology. www.whitehouse gov/sites/default/files/microsites/ostp/pcast-engage-to-excel-final _2-25-12.pdf (accessed 23 November 2015).

Russell SH, Hancock MP, McCullough J (2007). Benefits of undergraduate research experiences. Science 316, 548-549.

Summers MF, Hrabowski FA (2006). Preparing minority scientists and engineers. Science 311, 1870-1871.

Tinto V (1993). Leaving College: Rethinking the Causes and Cures of Student Attrition, 2nd ed., Chicago IL: University of Chicago Press.

Williams JC, Phillips KW, Hall EV (2014). Double Jeopardy? Gender Bias Against Women of Color in Science, San Francisco: University of California Hastings College of the Law. www.uchastings.edu/news/articles/2015/01/ double-jeopardy-report.pdf (accessed 15 August 2015).

Zorn P, Bailer J, Braddy L, Carpenter J, Jaco W, Turner P (2014). The INGenlOuS Project: Mathematics, Statistics, and Preparing the 21st Century Workforce, Washington, DC: Mathematical Association of America. www.maa.org/sites/default/files/pdf/ingenious/INGenlOuS-report.pdf (accessed 13 January 2016). 